\title{
The demise of nursing in the United Kingdom: a warning for medicine
}

\author{
Linda Shields ${ }^{1} \quad$ Roger Watson²
}

J R Soc Med 2007; 100:70-74

The 19th century teaches us that nurses must be central to the running of all aspects of hospitals, not just those areas deemed appropriate by the medical profession. This will require not only improved nursing leadership but also enhanced opportunities for nurses to realise their potential through education and training. ${ }^{1}$ (p. 1396)

Medicine without nursing is an untenable concept: doctors could not practice without highly educated, knowledgeable and competent nurses as part of the health care team. In the UK, nursing is under threat and could pass away, to be replaced by technicians, minimally educated health care assistants and unqualified health workers. Under the influence of pecuniary motives within the NHS, nursing as a role in health care is changing to encompass boundaries which have never been a part of a true nursing role before. Consequently, medical practice will be affected, and patient care compromised.

Some senior nurses are apprehensive about these changes and believe medicine should be equally concerned. This comments paper outlines such arguments, with the aim of enlisting medical colleagues to help in the debate.

\section{INTRODUCTION}

Black predicted the demise of the hospital, and related it to the state of nursing in the UK ${ }^{1}$. The demise of the hospital, and the National Health Service (NHS), seems to be pending in the UK with closures of hospitals and far reaching job cuts. Nursing can save the NHS, but to do so, needs a complete overhaul, professionally, in management style and, most importantly, in education. Currently, in the UK, nursing is dying, and the nurses are allowing it to happen; with no awareness of the threats, no preparation of funeral rites and no idea that extinction on a prehistoric

${ }^{1}$ Professor of Nursing, University of Hull, England, Honorary Professor, University of Queensland, Australia and University of Northumbria, Newcastleupon-Tyne, England; Visiting Fellow, Örebro University, Sweden; ${ }^{2}$ Professor of Nursing, University of Sheffield, England; Visiting Professor of Nursing, Hong Kong Polytechnic University, Hong Kong

Correspondence to: Professor Linda Shields, Faculty of Health \& Social Care, University of Hull, Cottingham Rd Hull HU6 7RX

E-mail: L.Shields@Hull.acuk scale is about to happen. This does not bode well for medicine, which requires highly educated, intelligent and motivated nurses to enable it to function, nor for the patients, who will be the biggest losers in this debacle.

Recent argument in medical journals discusses nurses assuming junior doctors' roles. Some doctors welcome this as a way to lighten their burden in a time of overstretched health budgets, increasingly older and sicker patients, burgeoning medical technology and increasing pressures for educational development. Others find anathema the idea of nurses taking on anything perceived to be a doctor's role. This is redolent of the arguments heard when nurses were allowed to use thermometers and sphygmomanometers. However, encouraging nurses to take on tasks which move them outside what is a distinctly different profession to medicine is not the answer. Such moves are exacerbated by several factors:

1. international shortage of nurses (and doctors);

2. increasing costs of technological health care and people's expectations of it;

3. the dire situation of nursing in the UK.

\section{NURSING EDUCATION}

University education for nurses was first postulated in the early 1900s in the United States and the 1940s in Australia, though it was not until the 1970s and 1990s respectively that it became mainstream. Australia now requires a bachelor's degree for nursing registration, as do most US states. While UK universities began offering nursing degrees in 1960, in 2005-6, 4\% of nurses are educated to degree level and the Nursing and Midwifery Council (NMC) requires only a diploma for registration. In Scotland and Wales, moves are afoot to make a degree the minimum qualification, but England is not following suit. Nurses who graduate with (usually honours) degrees are disadvantaged, as there is no recognition, better jobs or student funding that follows the higher qualification. Consequently, there is no incentive to read for a degree, though it is only through a degree that a student can adequately gain the knowledge needed to care for people in this time of highly technological health care, complex drug and treatment regimens, emerging diseases, complicated monitoring, 
convoluted management structures and difficult infection control. From a nursing workforce in which the level of education is so low, few will be qualified to assume the most junior of doctors' roles. Why do nurses want to do these roles? Do they see it as sophisticated? Perhaps that this is how it is being sold to them, but nurses are remiss in not understanding that these tasks are 'crumbs under the table', and are being given (the word is used advisedly) to them by doctors who no longer see history taking, intravenous cannulation, and other tasks perceived as menial, to be part of doctoring.

Legal responsibility for nursing care lies solely with the registered nurse $(\mathrm{RN})$. If one holds such heavy responsibility, one needs the highest level of education possible. In a controlled study of over 27000 hospital admissions in Pennsylvania, US, the odds of 30-day mortality and failure to rescue were $19 \%$ lower in hospitals where $60 \%$ of the nurses had bachelor or higher degrees than in hospitals where only $20 \%$ of nurses had degrees. Educating nurses to the highest standards is better for the health of all, and is cost effective. The consequences of poor education and mistakes are deaths, so the imperative to educate nurses to the highest standard, to provide them with ways to access the best evidence, the critical thinking skills to use that evidence safely and the skills to generate their own knowledge is mandatory.

\section{THE DEATH OF NURSING}

In the UK, nursing is haemorrhaging knowledge, skills and people from all sides. Unqualified health care assistants are taking nursing skills, as cheaper workers with scant education are replacing RNs. While these workers may be able to, for example, make the bed of, and feed, a stroke patient, they cannot assess skin condition, or the effects of facial paralysis while they are so doing, nor assess the effects of the person's illness on the family. A RN does all these, and plans care from this information.

Nursing is losing people laterally, as, in an egregious myopia, technicians are allowed to expropriate nurses' knowledge and skills. The technological function of performing the task is covered, but no care is given. One example is operating department practitioners (ODPs). These are trained to hand instruments to the surgeon, but have none of the knowledge of well educated, specialist perioperative nurses, who provide complete care for patients having surgery. While they, too, hand instruments, they also provide all care required by patients passing through the complex processes of an operating theatre. A perioperative nurse assumes responsibility for patients once they enter the theatre suite, check the right person is having the right procedure; ensure potential hazards are documented; ensure the site is prepared and, most importantly, discuss the operation with the patient and family to ascertain any anxiety about the surgery. Perioperative nurses liaise with anaesthetists, and prepare for positioning on the table, placement of machines, trolleys and tables to maximise comfort for the patient and ease of access for the surgeon and anaesthetist. Liaison with recovery staff begins when the patient enters the suite; they support the family and advise them of progress of the operation. In recovery, the perioperative nurse makes sure that patients are breathing effectively, is conscious, warm, pain free and with an intact wound before discharging them to the ward. Perioperative nurses make important clinical judgements, rather than just tasks associated with surgery, and patient-centred care is their core business. In contrast, technicians fulfill tasks associated with surgical procedures. As well as ODPs, the UK is producing endoscopy, anaesthetic, intravenous therapy, electrocardiograph and other technicians. All these were once exclusively nursing roles.

Nursing is trespassing on traditional medical territory. Doctors are in as short supply as nurses. Managers are looking to employ someone cheaper to take on junior doctors' roles. Enter the nurse practitioner. In some areas of health care, nurses justifiably take on doctors' roles. Remote area nurses in outback Australia, or in the cold north of Canada, whose practice and patients are thousands of miles from medical care, until the 1990s, worked illegally when they dispensed drugs, sutured wounds, diagnosed and treated illnesses. Without them, people would not be able to live in remote areas. It was ludicrous when nurses worked outside the law to deliver health care because few doctors would work in remote areas. Such procedures are now legal, and these nurses, in both countries, hold Master's degrees and are supported by intensive in-service education and outreach programmes.

\section{CURRENT TRENDS IN THE UK}

Most of the problems with nursing lie within the profession itself. For many years, nurses blamed doctors for their ills, though historical evidence is emerging that, in many countries, when university education for nurses was first mooted, it was often doctors who made the suggestion, and nurses who vehemently opposed it. Such attitudes still exist. The recent 'modern matron' initiative in the UK illustrates such thinking. Using titles such as 'matron' is singularly unhelpful to a profession trying to demonstrate that it has moved on since the 1960s, and one wonders about the self-perceptions of men who take this title. Nurses are being pressured to resume domestic roles. The NHS made cleaning of wards a nursing responsibility, a regression on improvements in the role of nurses since the 
1960s, which can be construed as: (a) saving on costs of proper corporate services, and (b) a way to oppress nursing by those with vested interests in ensuring nursing does not become too powerful, namely politicians balancing budgets of the ailing NHS.

\section{DIFFERENT PERSPECTIVES}

In Sweden, medicine and nursing are equal partners. Australian nurses are educated to similar levels as doctors. Registration requires a degree, specialisation is through postgraduate study and, commonly, nurses in ordinary positions hold at least a Master's degree. Nurses confidently advocate for patients as they possess critical thinking and life-long learning skills which ensure they can effectively find, use and generate evidence. Doctors at first felt threatened by this, but now acknowledge nurses as equal partners, able to work autonomously and drive their own profession. Currently, nurses hold many positions previously held by doctors: some chief executive officers of Australian health facilities are nurses; health portfolios at government executive level are held by nurses; and nurses chair important national committees. In the Republic of Ireland, all nursing education is now to degree level. Plans are afoot for the same in Scotland and Wales. Why has this not occurred in England?

Two important journals are published in Britain: Journal of Clinical Nursing and Journal of Advanced Nursing. Most of their submissions come from overseas. The UK content is from a handful of universities and health services, exemplary places where real evidence generation is prized and encouraged. However, in most nursing journals, much of the 'research' published in the UK is audit, evaluation of programmes, or initiatives driven by the NHS. A recent report from the Higher Education Policy Institute ${ }^{8}$ confirms this: 'It is striking how little the study of nursing appears to have been "academised" by its move to the Higher Education sector' (p.6), and 'research is a much less prominent feature of academic life in nursing departments than in academic departments generally' (Annex B, section 15).

Nursing education in England is funded by the Department of Health; in contrast, other disciplines are supported by the higher education funding bodies. This leads to nursing students being recruited to local universities to serve local health needs and the local community with no recognition of the global community and invaluable knowledge that international and wider national experience can bring to local health problems.

Any practice discipline educated at university has two masters - the university, and the registering authority; for example, medicine has both the university and the General
Medical Council. Because of the way it is funded, nursing has three entities of control-university, NMC and NHS. The NHS is driven by the need for personnel to care for patients - the 'bums on seats' (in wards) approach. In NHS nursing education, research is considered ineligible for funding. Such total disregard for research is echoed in the NMC's Code of Professional Conduct, where research is mentioned only once and that is in relation to "deliver care based on current evidence, best practice and, where applicable, validated research when it is available' (p. 9). Of more concern is the complete omission of research from the document Competence for Entry to the Register (18 October 2005). This is directly opposite to codes of ethics and professional practice from the International Council of Nurses, who say 'Research-based practice is a hallmark of professional nursing. Nursing research, both qualitative and quantitative, is critical for quality, cost-effective health care'. Research figures prominently in policies from, for example, Canada, Australia, Singapore and Thailand. While research is mentioned in some NHS documents, examination of NHS supported research done by nurses demonstrates that it generates little new knowledge, and other professions regard research done by nurses with disdain.

Another negative influence on nursing education in the UK is the three trimester, rather than two-semester university year with multiple intakes of hundreds. Because the government wants qualified nurses quickly, as many students as possible pass through universities. Lecturers finish marking student assessments one day and start a new round of lectures the next, delivering the same lecture up to four times a year, leaving no time for their own development and research. Would other disciplines, such as historians, scientists or doctors, tolerate these conditions and poor standards for students?

Entry levels to nursing in many universities across the UK are low. Oxford and Cambridge refuse to engage with nursing education, and the University of Sheffield has discontinued pre-registration programmes. Many nursing courses allow students with only five GCSEs to enter. 'Widening participation' is laudable, but only if it provides support and extra time for students who would not normally be able to enter university. To allow students with low entry criteria to undertake the same classes as high achieving students without appropriate support is patronising, and sets them up for failure. It commonly occurs that the level at which the classes are taught is decreased to that of the poorest student. The cadet nurse initiative, rekindled in the wake of Making a Difference (DoH 1999) was meant to widen access and increase the intake to nurse training of a wider range of minority ethnic groups and people with nontraditional educational backgrounds. However, this has failed. ${ }^{20}$ 


\section{INFLUENCES ON DEVELOPMENT}

The major problem confronting health services worldwide is the international shortage of health professionals. Importing nurses (or doctors) from developing countries to fill vacancies is no solution, as this depletes their nursing work force. ${ }^{4}$ Having universities produce qualified nurses en masse, with little regard to standards, resolves nothing. Only universities and the highest academic standards should be used to educate RNs. However, there are people within the community who want to be nurses, but who do not want (nor have the ability) to complete a degree, nor do they want the legal responsibility that a RN holds. They can be educated in colleges of further education to enrolled nurse level. Universities should educate only bachelor and higher degree students, and generate research. Higher education council funding rather than health service funding would ensure universities retain independence and autonomy over the degree curricula (while meeting standards for registration set by the NMC). However, the NMC standards need revision to include reference to the need for competence in generating, conducting and using research.

Nursing is changing rapidly. Emerging diseases such as avian influenza, Severe Acute Respiratory Syndrome and others will have a profound effect not just on the practicalities of nursing, but on the need for education in philosophy and ethics. The burgeoning increase in technology used in health care means nurses require indepth knowledge of physics, chemistry, biological science and genomics. At the same time, shortened hospital stays are creating the need for advanced community and public health resources, and nurses who can work independently. Infection control requirements are changing as antibiotic resistance demands modifications in the way hospitals work, and nurses need complex knowledge of pharmacology, pathology and microbiology. Ageing populations require nursing to adapt to increases in age-related illness and dependence, while the nursing workforce itself ages.

Military nursing has traditionally led in areas such as emergency care. However, military nurses participate in peacekeeping missions, where they deliver babies and nurse children, families, and the aged. Nurses involved in disaster relief work for both non-government organisations on long term sustainable relief efforts or for government aid projects as first responders in natural disasters and emergencies. HIV/ AIDS has created new dimensions, when, in the poorest nations, nurses provide care to the dying while they themselves and their families suffer. Terrorism affects nursing. The practicalities of caring for civilians who have been intentionally harmed are complicated by the ethics of caring for terrorists and their families. Nursing provides care for asylum seekers, whose health needs are compounded by psychological trauma and disempowerment of displacement.
It is imperative that nursing becomes an attractive option for school leavers with the intellectual ability to undertake academic study. If nursing roles are given to technicians, and nurses take on the jobs that doctors do not want, nursing will die, and consequences to the community will be severe. In the future, patients will be looked after by health care assistants, who might make beds and wipe bottoms, but will not be able to see a pressure area forming.

Patients will be taken to the operating theatre and deposited on the table by an orderly because there is no perioperative nurse to assess fitness for operation and support families. Anaesthetics will be given by technicians who might know how to adjust the gasses but will not know what to do for laryngospasm. Endoscopies will be done by someone with rudimentary education on its technologies, but who may not recognise abnormalities, something that has taken doctors decades to learn. In general practice, nurses will treat illnesses, but it would be preferable for him or her to do an in-depth assessment, dressings, give immunisations, discuss how patients' lives are affected by their illness, and co-ordinate care.

\section{CONCLUSIONS}

So where to from here? Nursing must wake up to what is happening, despite the political incorrectness of this position. Medicine must be made aware that the demise of nursing is not in its best interests, especially in the long term. Politicians must be persuaded that assassinating nursing in misplaced attempts at cost cutting ultimately carries electoral backlash, especially if patients die from unskilled or inadequate care. Most importantly, the public must be made aware, so that their rights as health consumers are abrogated no further by the demise of nursing.

\section{REFERENCES}

1 Black N. Rise and demise of the hospital: a reappraisal. BMJ 2005;331:1394-6

2 British Medical Journal: personal views. The nursing profession's coming of age. BMJ 2005;331:1415. http://bmj.bmjjournals.com/cgi/ content/extract/331/7529/1415. Accessed June 32006

3 Buchan J, Calman L. The global shortage of registered nurses: an overview of issues and actions. Geneva: International Council of Nurses, 2004

4 Editorial. Poaching nurses from the developing world. Lancet 2006;367:1791

5 Donahue MP. Nursing, the finest art : an illustrated history. St. Louis: C.V. Mosby, 1985

6 Longhurst R. In the footsteps of the Mercies: a history of nursing at the Mater Misericordiae Hospitals, Brisbane. South Brisbane: Mater Misericordiae Public Hospitals, 1992

7 Weir R. A leap in the dark. Penzance: Jamieson Library, 1996

8 Sastry T. The education and training of medical and health professionals in higher education institutions. London: Higher Education Policy Institute, 2005 
9 Aiken L, Clarke SP, Cheung RB, Sloane DM, Silber JH. Educational levels of hospital nurses and surgical patient mobility. JAMA 2003;290:1617-23

10 Hallett C. The 'Manchester scheme': a study of the Diploma in Community Nursing, the first pre-registration nursing programme in a British university. Nurs Inquir 2005;12:287-94

11 Watson R, Thompson DR (2003) Will modern matrons carry on regardless? J Nurs Manag 2003;11:67-68

12 Nursing and Midwifery Council. The NMC Code of Professional Conduct: standards for conduct, performance and ethics, standards 07/04. http://www.nmc-uk.org/(zy5zbcjz4wzmq555 cfqbhgyd)/aFrameDisplay. aspx?DocumentID=201 Accessed 3 June 2006

13 Nursing and Midwifery Council (2005). Competence for entry to the register. http://www.nmc-uk.org/(zy5zbcjz4wzmq555cfqbhgyd)/ aFrameDisplay.aspx?DocumentID=1036 Accessed 3 June 2006)

14 International Council of Nurses (1999) Position statement: nursing research 1999. http://www.icn.ch/psresearch99.htm. Accessed 3 June 2006
15 College of Nursing Ontario (2002). Professional Standards Revised 2002. http://www.cno.org/docs/prac/41006_ProfStds.pdf Accessed 3 June 2006

16 Australian Nursing and Midwifery Council (2005) National competency standards for the registered nurse 2005. http://www.anmc.org.au/ website/Publications / National\%20Standards/Competency $\% 20$ Standards \%20for\%20the\%20Registered\%20 Nurse.pdf. Accessed 3 June 2006

17 Singapore Nursing Board: Standards of Practice for Nurses and Midwives. 2006. http://www.snb.gov.sg/ Accessed 3 June 2006

18 The Nursing Council of Thailand About us: Code of Ethics. 2004. http: / / www.moph.go.th/ngo/nursec/aboutus.htm Accessed 3 June 2006

19 Department of Health. Making a Difference. London: Department of Health, 1999

20 Watson R, Norman IJ, Draper J, Jowett S, Wilson-Barnett J, Normand C, Halliday D (2005) NHS cadet schemes: do they widen access to healthcare study? J Adv Nurs. 2005;49:276-82

21 Watson R, Thompson DR. The Trojan horse of nursing education Nurse Educ Today 2003;24:73-5 